\title{
Process Optimization of Fenton Oxidation using
}

\section{Kinetic Modeling}

\author{
Supporting Information
}

\author{
Christopher K. Duesterberg and T. David Waite
}

School of Civil and Environmental Engineering, The University of New South Wales

Sydney, NSW 2052, Australia

Submitted to:

Environmental Science and Technology

April 2006

Corresponding author: Phone +61-2-9385 5060, Fax +61-2-9385 6139, Email

d.waite@unsw.edu.au 


\section{Appendices}

A1. Formic Acid Oxidation by Hydroxyl Radicals

A2. Efficiency and $\mathrm{H}_{2} \mathrm{O}_{2}$ Dosing Regimes

A3. Presence / Absence of Oxygen 


\section{A1. Formic Acid Oxidation by Hydroxyl Radicals}

Table S1: Mechanism for $\mathrm{HCOOH} / \mathrm{HCOO}^{-}$Oxidation by ${ }^{\bullet} \mathrm{OH}$

\begin{tabular}{|c|c|c|c|c|}
\hline \multirow{2}{*}{\multicolumn{2}{|c|}{ Reaction }} & \multicolumn{3}{|c|}{ Rate Constant $\left(\mathrm{M}^{-1} \mathrm{~s}^{-1}\right)$} \\
\hline & & pH 3 & pH 4 & Ref \\
\hline 10 & ${ }^{\bullet} \mathrm{OH}+\mathrm{HCOOH} \rightarrow \mathrm{HCOO}^{\bullet}+\mathrm{H}_{2} \mathrm{O}$ & $1.08 \times 10^{8}$ & $4.31 \times 10^{7}$ & $\begin{array}{l}\text { this } \\
\text { study }\end{array}$ \\
\hline 11 & ${ }^{\bullet} \mathrm{OH}+\mathrm{HCOOH} \rightarrow \mathrm{CO}_{2}^{\bullet-}+\mathrm{H}_{2} \mathrm{O}+\mathrm{H}^{+}$ & $5.42 \times 10^{8}$ & $2.16 \times 10^{9}$ & (1) \\
\hline 12 & $\mathrm{HCOO}^{\bullet}+\mathrm{O}_{2} \rightarrow \mathrm{CO}_{2}+\mathrm{HO}_{2}^{\bullet} / \mathrm{O}_{2}^{\bullet-}$ & $4.20 \times 10^{9}$ & $4.20 \times 10^{9}$ & $(2)$ \\
\hline 13 & $\mathrm{CO}_{2}^{\bullet-}+\mathrm{O}_{2}+\mathrm{H}^{+} \rightarrow \mathrm{CO}_{2}+\mathrm{HO}_{2}^{\bullet} / \mathrm{O}_{2}^{\bullet-}$ & $4.20 \times 10^{9}$ & $4.20 \times 10^{9}$ & (2) \\
\hline 14 & $\mathrm{CO}_{2}{ }^{\bullet-}+\mathrm{CO}_{2}^{\bullet-} \rightarrow \mathrm{Int}$ & $1.40 \times 10^{9}$ & $1.40 \times 10^{9}$ & $(2)$ \\
\hline 15 & $\mathrm{Int}+\mathrm{H}^{+} \rightarrow \mathrm{CO}_{2}+\mathrm{HCOOH}$ & $1.00 \times 10^{10}$ & $1.00 \times 10^{10}$ & $(2)$ \\
\hline 16 & Int $\rightarrow$ Oxalate & $1.60 \times 10^{6}$ & $1.60 \times 10^{6}$ & (2) \\
\hline 17 & $\mathrm{HCOO}^{\bullet}+\mathrm{HCOO}^{\bullet} \rightarrow \mathrm{CO}_{2}+\mathrm{HCOOH}$ & $1.70 \times 10^{9}$ & $1.70 \times 10^{9}$ & (2) \\
\hline 18 & $\mathrm{HCOO}^{\bullet}+\mathrm{CO}_{2}^{\bullet-}+\mathrm{H}^{+} \rightarrow \mathrm{CO}_{2}+\mathrm{HCOOH}$ & $1.70 \times 10^{9}$ & $1.70 \times 10^{9}$ & $(2)$ \\
\hline 19 & $\mathrm{CO}_{2}^{\bullet-}+\mathrm{Fe}(\mathrm{III}) \rightarrow \mathrm{CO}_{2}+\mathrm{Fe}(\mathrm{II})$ & $2.77 \times 10^{6}$ & $2.77 \times 10^{6}$ & (2) \\
\hline 20 & $\mathrm{HCOO}^{\bullet}+\mathrm{Fe}(\mathrm{III}) \rightarrow \mathrm{CO}_{2}+\mathrm{Fe}(\mathrm{II})+\mathrm{H}^{+}$ & $1.00 \times 10^{5}$ & $1.00 \times 10^{5}$ & $(2)$ \\
\hline
\end{tabular}

Table S1 presents the decomposition pathway of formic acid by hydroxyl radicals.

Previous studies (2-4) have demonstrated that formic acid oxidation by ${ }^{\bullet} \mathrm{OH}$ proceeds through the carboxyl radical intermediate, $\mathrm{HCOO}^{\bullet} / \mathrm{COO}^{\bullet}$. Recognized as a strong reducing agent (2), the carboxyl radical reacts with oxygen at diffusion-limited rates to yield $\mathrm{CO}_{2}$ and superoxide (5-6). Results of experiments and simulations in the absence of oxygen have supported the direct reduction of $\mathrm{Fe}$ (III) by carboxyl radicals (reactions 19 and 20), with the rate constants $k_{20}$ and $k_{21}$ being determined by numerical optimization routines fitted to experimental data (7). Under conditions where $[\mathrm{HCOOH}]_{0}>[\mathrm{Fe}(\mathrm{II})]_{0}$, $\left[\mathrm{H}_{2} \mathrm{O}_{2}\right]_{0}$ and in the absence of oxygen, laboratory and model data have shown these radicals play a significant role in the redox cycling of iron (7).

It should be noted that reactions 10 and 11 in Table 2 contain the same reactants but different product species in the protonated and deprotonated forms of the carboxyl radical. While for other weakly acidic species composite rate constants have been calculated to account for such equilibrium speciation, the carboxyl radical is treated 
differently due to the differing products generated by disproportionation of the carboxyl radical anion (reactions $14-16$ ) and the carboxyl radical (reactions 17 and 18). One of these products, oxalate, is known to be a strong $\mathrm{Fe}(\mathrm{III})$ complexant with significant influence on the iron redox cycle (8). In all kinetic simulations conducted for this work, however, the maximum oxalate concentration is never more than two percent of the total iron concentration, so effects arising from $\mathrm{Fe}$ (III) complexation were considered negligible. The rate constants $k_{10}$ and $k_{11}$ were calculated such that $\left[\mathrm{COO}^{\circ}\right]_{\mathrm{t}}$ and $\left[\mathrm{HCOO}^{\circ}\right]_{\mathrm{t}}$ correspond to the appropriate fraction of the total carboxyl radical concentration at the given $\mathrm{pH}$ using a $\mathrm{pK}_{\mathrm{a}}$ value of 2.3 (2).

\section{References}

(1) Kwan, W.P.; Voelker, B.M. Decomposition of Hydrogen Peroxide and Organic Compounds in the Presence of Dissolved Iron and Ferrihydrite. Environ. Sci. Technol. 2002, 36, 1467-1476.

(2) Flyunt, R.; Schuchmann, M.N.; Von Sonntag, C. A common carbanion intermediate in the recombination and proton-catalysed disproportionation of the carboxyl radial anion, $\mathrm{CO}_{2}{ }^{\bullet-}$, in aqueous solution. Chem. Eur. J. 2001, 7, 796-799.

(3) Allen, A.O. The Radiation Chemistry of Water and Aqueous Solutions; Van Nostrand: Princeton, New Jersey, 1961; pp. 117-140.

(4) Buxton, G.V.; Sellers, R.M. Acid Dissociation Constant of the Carboxyl Radical. J. Chem. Soc. Faraday Trans. 1 1973, 69, 555-559.

(5) Baxendale, J.H.; Khan, A.A. The Pulse Radiolysis of $p$-Nitrosodimethylaniline in Aqueous Solution. Int. J. Radiat. Phys. Chem. 1969, 1, 11-24.

(6) Ilan, Y.; Rabani, J. On Some Fundamental Reactions in Radiation Chemistry: Nanonsecond Pulse Radiolysis. Int. J. Radiat. Phys. Chem. 1976, 8, 609-611.

(7) Duesterberg, C.K.; Cooper, W.J.; Waite, T.D. Fenton-Mediated Oxidation in the Presence and Absence of Oxygen. Environ. Sci. Technol. 2005, 39, 5052-5058.

(8) Sedlak, D.L.; Hoigné, J. The Role of Copper and Oxalate in the Redox Cycling of Iron in Atmospheric Waters. Atmospheric Environment 1993, 27A, 2173-2185. 


\section{A2. Efficiency and $\mathrm{H}_{2} \mathrm{O}_{2}$ Dosing Regimes}

\section{Figure S1}
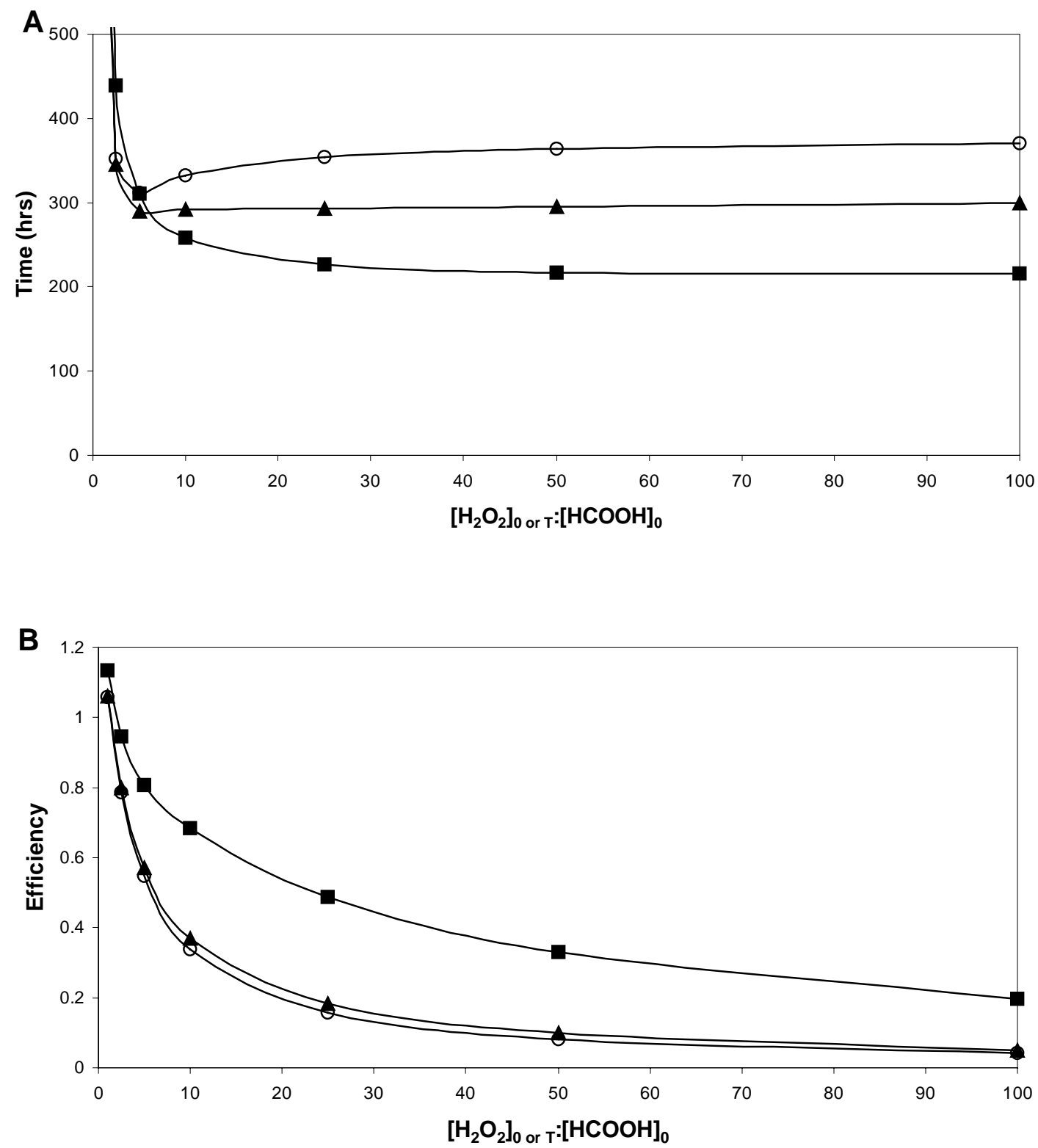

Figure S1: Results of kinetic simulations showing A) the time required to reach $90 \%$ oxidation of $\mathrm{HCOOH}$, and $\mathrm{B}$ ) the efficiency (mol $\mathrm{HCOOH}$ oxidized / $\mathrm{mol} \mathrm{H}_{2} \mathrm{O}_{2}$ consumed) of the system at $90 \%$ oxidation, using different $\mathrm{H}_{2} \mathrm{O}_{2}$ dosing regimes. Initial conditions: $[\mathrm{Fe}(\mathrm{II})]_{0}$ and $[\mathrm{HCOOH}]_{0}=400 \mathrm{nM}, \mathrm{pH}=$ 3 , air-saturated solutions. The total amount of $\mathrm{H}_{2} \mathrm{O}_{2}$ added is introduced as a single batch addition $(0)$, fed continuously into the system over a 10 hour period $(\mathbf{\Lambda})$, or fed continuously over the period required to reach $90 \%$ oxidation in a batch process ( $\mathbf{\square})$. 


\section{A3. Presence / Absence of Oxygen}

\section{Figure S2}

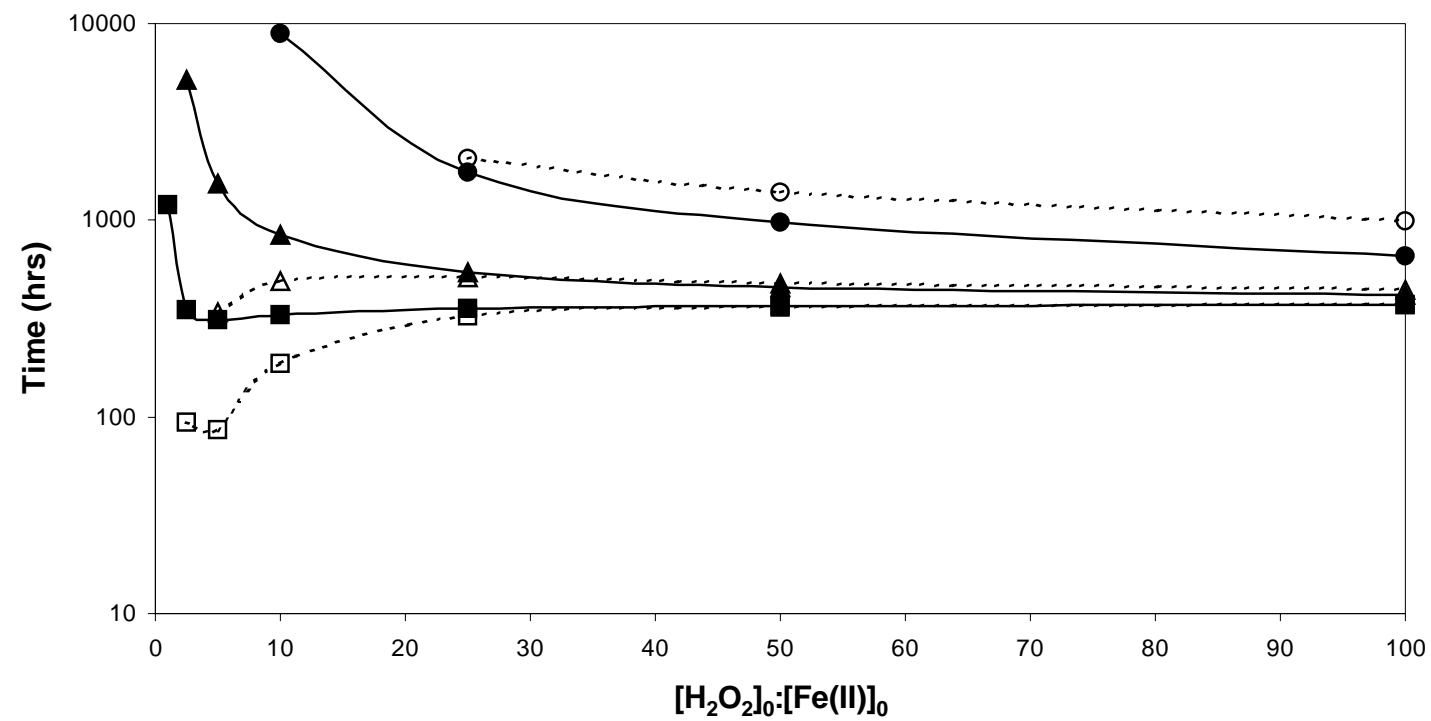

Figure S2: Results of kinetic simulations showing the time required to reach $90 \%$ oxidation of $\mathrm{HCOOH}$ at $\mathrm{pH} 3$ in the presence (solid lines) and absence (dashed lines) of oxygen. Initial conditions: $[\mathrm{Fe}(\mathrm{II})]_{0}=$ $400 \mathrm{nM},[\mathrm{HCOOH}]_{0}:[\mathrm{Fe}(\mathrm{II})]_{0}=1(\boldsymbol{\bullet}), 2.5(\boldsymbol{\Delta})$, and $10(\bullet)$. 